\title{
Carbon Emission Efficiency Measurement of Construction Industry and Its Treatment Measures-A Case Study of Henan Province, China
}

\author{
Zhang Hui*†, Du Liu Jie**, Wang Bai Tian** and Qi Ping* \\ *Institute of Architecture Engineering, Huanghuai University, Zhumadian 463000, China \\ **College of Architecture and Civil Engineering, Shangqiu University, Shangqiu 476000, China \\ †Corresponding author: Zhang Hui: zhhui106@126.com
}

Nat. Env. \& Poll. Tech.

Website: www.neptjournal.com

Received: 13-02-2021

Revised: 15-03-2021

Accepted: 08-04-2021

Key Words:

Construction industry

Carbon emission efficiency

Treatment measures

\begin{abstract}
Energy demand and carbon emission in building construction and utilization have presented an increasing trend with urbanization development and improvement of living standard. Improving the carbon emission efficiency of the construction industry is a precondition for allocating carbon emission reduction objectives and interregional experience exchange over carbon emission reduction. An inputoutput index system was first constructed in this study to obtain the carbon emission efficiency of the construction industry. Carbon dioxide emission of the construction industry was taken as unexpected output, and the super efficiency slack-based measure-data envelopment analysis (SBM-DEA) model was used to estimate the carbon emission efficiency of the construction industry in Henan Province, China during 2008-2019. Finally, treatment measures were proposed to retard the rising trend of carbon emission in the construction industry. Results showed that the mean carbon emission efficiency of the construction industry in Henan Province during 2008-2019 is 1.007 and the carbon emission efficiency of the construction industry reaches the minimum value of only 0.807 in 2012 . The carbon emission efficiency of the construction industry in Henan Province demonstrated an overall rising trend with a small amplitude during the investigation period. The results of this study can provide a reference for exploring the efficiency of the construction industry in Henan Province under carbon emission constraint, analyzing and identifying efficiency improvement objectives and methods for the construction industry, and facilitating its sustainable development.
\end{abstract}

\section{INTRODUCTION}

China is in the high-speed development phase of industrialization, urbanization, and modernization at present. Although the country's economy maintains a fast growth trend, serious and realistic problems, such as high energy consumption and emission, still persist. As the pillar industry of national economic development that plays a crucial role in China's economic construction process, the construction industry has progressed considerably in recent years while imposing non-negligible environmental stress on economic development. Moreover, this industry is closely related to national economic development and the improvement of people's livelihood. The construction industry has boosted the national economic development, promoted social progress, and provided job opportunities and material support to relevant national economic sectors with consideration for its industrial characteristics. Meanwhile, building energy conservation demonstrates high potential in solving the future global energy plight and realizing carbon emission reduction. All levels of the Chinese government have aggressively supported the development of a low- carbon economy and promotion of green buildings in the construction industry in recent years. Different regions have achieved an evident decrease in carbon emission intensity and satisfactory progress in energy conservation and emission reduction in the construction industry, with a substantial decrease in the number of heavy pollution days and improved overall air quality.

The construction industry is a typical energy-intensive field characterized by high energy consumption, high emission, and low efficiency. As shown in Fig. 1, the gross domestic product (GDP) of the construction industry in Henan Province, China is steadily increasing from RMB $282,405,000,000$ in 2008 to RMB $1,270,168,000,000$ in 2019 , with an annual average growth rate of up to $16.19 \%$. However, this industry still maintains an extensive development pattern of high input and output that results in inefficient resource utilization, increasing pollutant emissions, and surplus carbon emission. The development pattern of the construction industry in Henan Province must be transformed to enhance its efficiency and maintain pace with the rapid social development and needs of the general public. The production efficiency of this industry must be improved to 


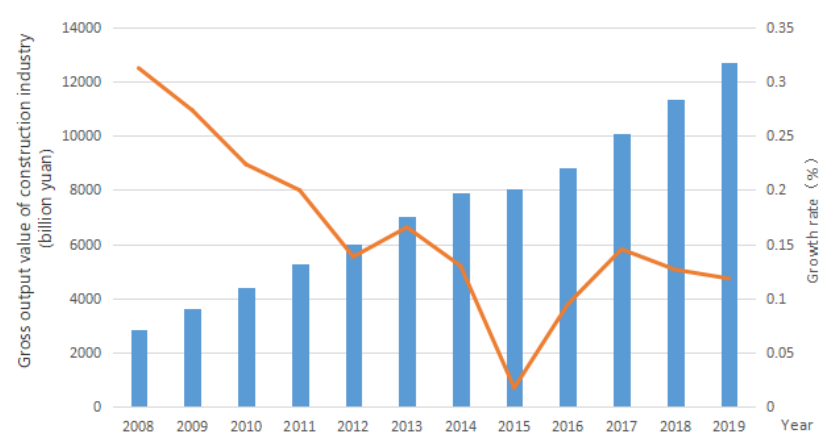

Fig. 1: Gross Output Value and Growth Rate of the Construction Industry in Henan Province During 2008-2019.

acquire high output while reducing the cost; reach the optimal input-output relation; and use the sustainable, efficient, and energy-saving development approach to replace the extensive development pattern.

\section{PAST STUDIES}

The current carbon emission of the construction industry is mainly calculated from microscopic and macroscopic angles. The carbon emission of the construction industry is accounted for with a specified area from the macroscopic angle. Domestic (Chinese) and foreign scholars have analyzed environmental influencing factors by focusing on the industrial field as well as technical efficiency, carbon emission efficiency, and economic growth of the industry. Many methods have been proposed to determine the carbon emission efficiency of the construction industry. Cole, R. J. provided a detailed calculation method for analyzing the energy consumption and greenhouse gas emission induced by field construction in the construction industry (Cole 1999). Chau et al. evaluated the building efficiency of construction companies in Hong Kong and revealed that high technical efficiency benefits from cost-effectiveness, large scale, low degree of subcontracting of construction companies, and low proportion of intermediate input consumption (Chau et al. 2001). Ramanathan used data envelopment analysis (DEA) to examine associations among gross national product (GNP), energy consumption, and carbon emission and showed that the carbon emission efficiency varies occasionally (Ramanathan 2006). Colombier et al. expounded on construction energy conservation technology featured by low carbon emission and sustainable development considered the urban construction industry in China as the study object and demonstrated that this technology can reduce the carbon emission and decelerate climatic changes (Colombier et al. 2009). Fan et al. indicated that building construction exerts a very important influence on the environment and a considerable amount of energy will be consumed while substantial greenhouse gases will be emitted in the production, transportation, and installation of construction materials and subsequently conducted a case study on greenhouse gas emission in building construction; the results showed that greenhouse gas emissions of construction materials account for $82 \%-87 \%$ of the total (Fan et al. 2010). Monahan et al. put forward process-based life cycle assessment (LCA) method to estimate carbon emissions of China's construction industry and pointed out that the total energy consumed by the industry is 411 million tce in 2016 and construction activities of city residential, public, and commercial buildings replace rural residences to become the main source of energy consumption and emission (Monahan et al. 2011). Acquaye et al. identified and analyzed emission "hotspots" in the product life cycle using different intervention schemes in the supply chain to reduce greenhouse emissions (Acquaye et al. 2015). Wang et al. proposed a method for calculating emissions in the total life cycle of China's construction industry and introduced multicriteria Gini coefficient as an index of emission permit allocation; the results showed that the overall emission in China's construction industry is increasing, with the maximum emission amount in the building production phase (Wang et al. 2017). Huang et al. stated that the construction industry consumes a large quantity of nonrenewable energy resources and the total $\mathrm{CO}_{2}$ emission of the global construction industry has reached 5.7 billion tons, which accounts for $23 \%$ of the total $\mathrm{CO}_{2}$ emission from global economic activities in 2009 (Huang et al. 2018). Li et al. calculated direct and indirect carbon emissions during the building foundation and structural construction processes and determined carbon emission sources in the two important construction phases ( $\mathrm{Li}$ et al. 2017). Cai et al. pointed out that the energy consumption of the construction industry is calculated as a dependentenergy consumption type and should be divided and blended into other industries of China's statistical system and subsequently proposed a concrete method for estimating the carbon emission of the construction industry (Cai et al. 2018). Fang et al. demonstrated that the construction industry can realize clean and sustainable building production and construction and proposed a method for measuring carbon emissions in the construction phase due to the difficulty in calculating carbon emissions from complicated construction processes and numerous participators (Fang et al. 2018). Du et al. investigated club convergence and spatial distribution dynamics of carbon intensity in China's construction industry during 2005-2014; the results showed that carbon intensities of the construction industry in different provinces of China present a "convergence club" characteristic during the study period; extremely low or high level of convergence club indicates strong stability (Du et al. 2018). Zhou et al. showed 
that the construction industry is the primary source of carbon emissions in China's economy and used the superslack-based measure-data envelope analysis (super-SBM-DEA) method to estimate the total-factor carbon emission efficiency of the construction industry during 2003-2016; the results showed that the low carbon emission efficiency in China's construction industry presents a declining trend (Zhou et al. 2019). Lu et al. critically reviewed and summarized carbon emissions of green buildings and proposed a comprehensive life-cycle carbon-emission evaluation model (Lu et al. 2020). These studies showed that the production in the construction industry needs a considerable amount of labour, material, and financial inputs, including energy sources and technologies. Studies on the efficiency evaluation of the construction industry have considered labour force, capital, and technology while neglecting environmental factors. Accordingly, the carbon emission of the construction industry was taken as the unexpected output based on the life cycle theory of the construction industry and the slack-based measure-data envelope analysis (SBM-DEA) model was used in this study to estimate the carbon emission efficiency of the construction industry in Henan Province, China during 2008-2019. The SBM-DEA model can scientifically and effectively measure the carbon emission efficiency of the construction industry in Henan Province to realize energy conservation and emission reduction and improve the efficiency of the construction industry. This study can provide a theoretical basis for relevant departments in the construction industry and guidance in the production process of this industry.

\section{MODEL PROFILE AND INDEX SELECTION}

\section{SBM-DEA Model}

The super-efficiency SBM-DEA model developed from the DEA method is a nonparametric technical efficiency analysis method based on comparisons of evaluation objects. Input minimization and output maximization assumptions of the traditional DEA model have restricted its application in solving problems that consider unexpected outputs. Apart from expected outputs, practical production is usually accompanied by unexpected outputs, such as pollutant discharge and carbon emission. Tone combined the traditional DEA method, introduced the slack variable in the objective function, and proposed the SBM model containing unexpected outputs to solve the efficiency evaluation problem effectively while considering unexpected outputs (Tone 2001).

We assume that $n$ decision-making units (DMU) exist and each DMU is composed of three parts, namely, $m$ input indexes $(x), S_{1}$ expected outputs $\left(y_{d}\right)$, and $S_{2}$ unexpected outputs $\left(y_{u}\right)$, which can be expressed by the following matrix:

$$
X=\left[x_{1}, x_{2}, \ldots, x_{n}\right] \in R_{m \times n}>0,
$$

$$
\begin{gathered}
Y_{d}=\left[y_{d 1}, y_{d 2}, \ldots, y_{d n}\right] \in R_{s_{1} \times n}>0, \\
Y_{u}=\left[y_{u 1}, y_{u 2}, \ldots, y_{u n}\right] \in R_{s_{2} \times n}>0 .
\end{gathered}
$$

The production set established when this method is used can be expressed as follows:

$P=\left\{\left(x, y_{d}, y_{u}\right) \mid x>X \lambda, y_{d} \leq Y_{d} \lambda, y_{u} \leq Y_{U} \lambda, \lambda \geq 0\right\}, .$.

where $\lambda$ is the non-negative weight vector that expresses returns to scale while ignoring the production.

Slack variables $S_{-}, S_{d}$ and $S_{u}$ are added based on the traditional DEA model to express the input, expected output, and unexpected output slack variables, respectively, and form the following SBM efficiency evaluation model:

$$
\begin{gathered}
\rho=\min \frac{1-\frac{1}{m} \sum_{i=1}^{m} \overline{S_{i}} / x_{i 0}}{1-\frac{1}{s_{1}+S_{2}}\left(\sum_{r=1}^{s_{1}} S_{d r} / y_{d r 0}+\sum_{t=1}^{s_{2}} S_{u t} / y_{u t 0}\right)}, \\
\left\{\begin{array}{c}
x_{0}=X \lambda+S_{-} \\
y_{d 0}=Y_{d 0}-S_{d} \\
y_{u 0}=Y_{u 0}+S_{u} \\
S_{-} \geq 0, S_{d} \geq 0, S_{u} \geq 0, \lambda \geq 0
\end{array}\right.
\end{gathered}
$$

where $\rho$ is the carbon emission efficiency with a value range of $0-1$. The efficiency value is equal to 1 when $S_{-}=S_{d}=S_{u}$ $=0$, and the carbon emission of this DMU is considered efficient. DMUs with an efficiency value of 1 in the last calculation step should be further processed to distinguish multiple DMUs with an efficiency of 1 . The super-efficiency SBM model is expressed as follows:

$$
\begin{gathered}
\rho^{*}=\min \frac{1+\frac{1}{m} \sum_{i=1}^{m} \overline{S_{i}} / x_{i k}}{1-\frac{1}{S_{1}+S_{2}}\left(\sum_{r=1}^{s_{1}} S_{d r} / y_{d r k}+\sum_{k=1}^{s_{2}} S_{u k} / y_{u t k}\right)}, \\
x_{i k} \geq \sum_{j=1 \neq k}^{n} x_{i j} \lambda_{j}+S_{-i} \\
y_{d r k} \leq \sum_{j=1 \neq k}^{n} y_{d r j} \lambda_{j}+S_{d r} \\
y_{u k k} \geq \sum_{j=1 \neq k}^{n} y_{u j j} \lambda_{j}+S_{u t} \\
1-\frac{1}{S_{1}+S_{2}} \geq\left(\sum_{r=1}^{s_{1}} S_{d r} / y_{d r k}+\sum_{k=1}^{s_{2}} S_{u k} / y_{u k k}\right)>0 \\
S_{-} \geq 0, S_{d} \geq 0, S_{u} \geq 0, \lambda \geq 0 \\
r=1,2, \ldots, S_{2}, i=1,2, \ldots, m, j=1,2, \ldots, n(j \neq k)
\end{gathered},
$$

where small inputs and unexpected outputs indicate high expected outputs and efficiency value $\rho^{*}$.

\section{Index Selection}

The construction of the efficiency evaluation index system for the construction industry must incorporate not only the 
uniqueness of the construction industry but also combine national environmental protection policies and stipulations for energy conservation and emission reduction. The scientific and reasonableness of input and output indexes are closely related to those of follow-up work, such as efficiency evaluation. First, theory constantly differs from practice. Specifically, subjective factors affect input and output indexes selected and the constructed index system. The efficiency of the constructed index system varies due to the different preferences of people. Second, if the evaluation index system used is unreasonable, then the obtained result will remarkably deviate from the true value. The efficiency evaluation of the construction industry is affected by traditional factors, such as capital, equipment, and labour force. Finally, energy consumption and carbon emission also influence the construction industry because of the international situation and policies regarding energy conservation, emission reduction, and experimental protection. Hence, these factors must be considered in the selection of input and output indexes. The input-output index system shown in Table 1 is established by combining index systems in the existing literature and the data accessibility of the construction industry in Henan Province.

The labour-intensive construction industry highly promotes China's economic development and provides many employment positions to employees of construction enterprises (X1) (Table 1). The quantity of employee inputs can reflect the industry's development status. The efficiency level of the construction industry analyzed through the number of employees can measure the effectiveness of inputs. The labour productivity of construction enterprises (X2) calculated according to the gross output value of this industry measures the output quantity under the given labour input. The ratio of gross output value to quantity of employees in a specific period is generally defined as labour productivity. This index reflects the improvement or degradation of efficiency based on the increase or decrease in the output value of construction products caused by the labour input in different periods. Labour productivity represents technological progress. All kinds of materials, including mechanical production facilities and construction components, must be inputted in the production process of the construction industry to measure the technical equipment rate of construction enterprises (X3). The input of construction materials can reflect the efficiency status of the construction industry. However, the selection of construction materials to reflect the efficiency of the construction industry is not universally applicable because processes and management concepts used as well as the input quantity varies in each region. The index of total profits and taxes of construction enterprises (Y2) is used to investigate profits and taxes. Y2 sums profits and taxes to reflect all actual profits generated in different regions in the corresponding period and the quantized value of social obligations as well as manifests social benefits from the construction industry. Y2 is the index used to measure the output of the construction industry directly and represent construction products produced by the construction industry in one period in the form of total currency. The total output value of the construction industry in different regions can appropriately reflect the market occupancy and economic benefit of the construction industry in a specific region. The house construction area of the construction industry (Y3) reflects the total area output of building construction in the investigation period as an index directly used to measure the output of the construction industry. $\mathrm{CO}_{2}$ emission (Y4) is an unexpected output index generated by energy use in the construction industry. Y4, which was taken as the unexpected output in the SBM-DEA model in this study, is an important index used to measure the carbon emission efficiency of the construction industry.

All index and other data for the investigation period of 2008-2019 were derived from China statistical database. The $\mathrm{CO}_{2}$ emission was calculated following Guidelines for National Greenhouse Gas Inventories.

Table 1: Input-Output index system.

\begin{tabular}{|lll|}
\hline Index type & Index (unit) & Index code \\
\hline Input & Employees of construction enterprises (10,000 people) & X1 \\
Input & $\begin{array}{l}\text { Labour productivity of construction enterprises calculated according to the gross output value of the construction } \\
\text { industry (yuan/person) }\end{array}$ & X2 \\
Input & Technical equipment rate of construction enterprises (yuan/person) & X3 \\
Output & Total profits and taxes of construction enterprises (¥ 100 million) & Y1 \\
Output & Gross income of construction enterprises (¥ 100 million) & Y2 \\
Output & House construction area of the construction industry (10,000 m & \\
Unexpected output & $\mathrm{CO}_{2}$ emission (10,000 tons) & Y4 \\
\hline
\end{tabular}




\section{RESULT ANALYSIS}

Correlation coefficients among seven input and seven output indexes of the construction industry in Henan Province are listed in Table 2.

Table 2 presents that seven variables are highly correlated. The carbon emission efficiency of the construction industry in Henan Province during 2008-2019 was estimated using Formulas (1)-(4). Fig. 2 shows the 2008-2019 values calculated using DEA-SOLVER PRO software.

Fig. 2 shows the declining overall efficiency after the $\mathrm{CO}_{2}$ emission is taken as an unexpected output and included as an evaluation index for the construction industry in Henan Province. This finding indicated that the efficiency of the construction industry is affected by energy conservation and emission reduction policies. However, with ever-deepened importance attached by the nation and people to the environment, the efficiency evaluation of the construction industry that neglects environmental factors failed to conform with the practical situation. The carbon emission efficiency in Henan Province declined from 1.059 to 1.009 during 2008-2009 likely because the growth rate of the gross output value was small under the influence of the financial crisis in 2008. The increase of carbon emission efficiency from 1.010 to 1.011 during 2009-2010 showed a slow-growth trend likely due to the increase of the gross output value of the construction industry among inputs and outputs. Preparations for the "12th Five-Year Plan" in 2011 were conducted in the previous year. Energy conservation and emission reduction policies were carried out, and Henan Province achieved satisfactory progress in developing the construction industry under the controlled carbon emission. The efficiency value declined again in 2012 and reached the minimum value of 0.807 during the investigation period. This finding indicated that "Central Plains Economic Zone Planning" promoted the urbanization construction in Henan Province and drove the rapid development of the construction industry. However, the province failed to achieve the timely transformation to adapt to such development speed and requirements, and the past production pattern unsuccessfully maintained the effective status of the construction industry. However, the increase of efficiency again in 2013 manifested that the adaptability of the construction industry in Henan Province to the development was slightly enhanced, timely adjustments were performed after the efficiency dropped,

Table 2: Correlation coefficients among seven input and seven output indexes

\begin{tabular}{|llllllll|}
\hline & $X 1$ & $X 2$ & $X 3$ & $Y 1$ & $Y 2$ & $Y 3$ \\
$X 1$ & 1 & 0.857 & 0.257 & 0.957 & 0.934 & 0.916 & 0.949 \\
$X 3$ & 0.857 & 1 & 0.373 & 0.93 & 0.961 & 0.954 \\
$Y 1$ & 0.257 & 0.373 & 1 & 0.326 & 0.422 & 0.507 \\
$Y 2$ & 0.957 & 0.93 & 0.326 & 1 & 0.986 & 0.971 & 0.431 \\
$Y 3$ & 0.934 & 0.961 & 0.422 & 0.986 & 1 & 0.97 & 0.951 \\
$Y 4$ & 0.916 & 0.954 & 0.507 & 0.971 & 0.991 & 0.953 \\
\hline
\end{tabular}

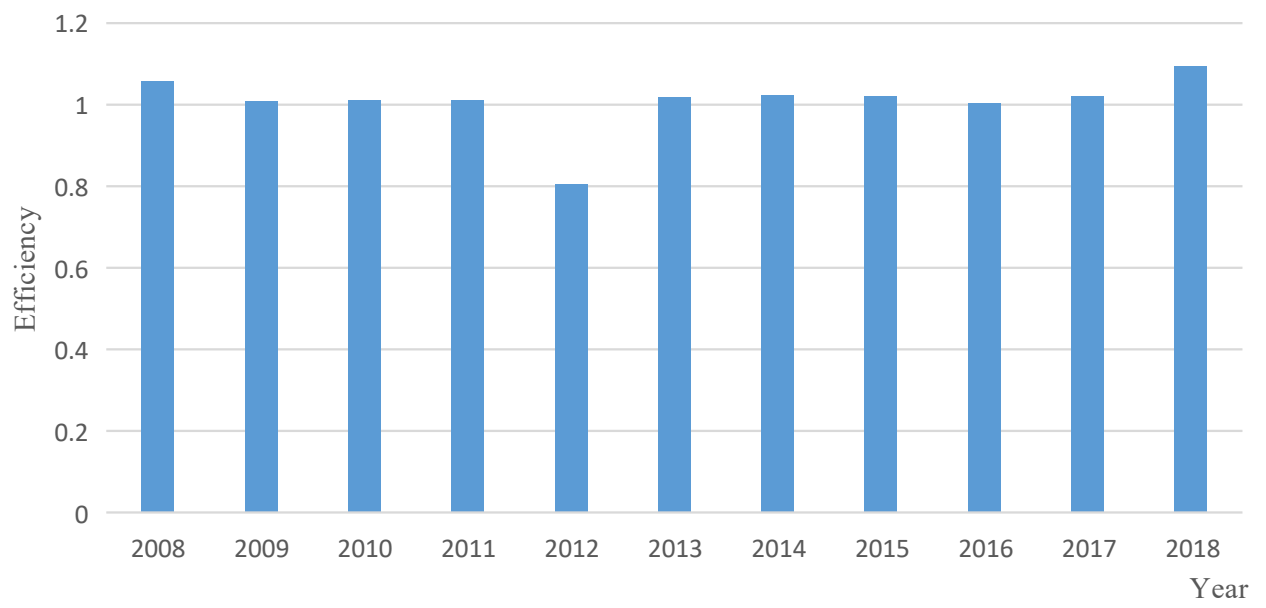

Fig. 2: Carbon emission efficiency of the construction industry in Henan Province During 2008-2019. 
and measures were taken to improve the efficiency. The carbon emission efficiency reached its peak at 1.094 in 2018 due to the enhancements applied by the Chinese government in environmental protection while developing the national economy. Multiple plans were formulated for the construction industry to cope with the increasingly enhanced environmental protection effectively. Henan Province actively carried out national policies to determine suitable development patterns. The overall efficiency of the construction industry during this process increased, but the small increase amplitude reflected a large improvement space for the carbon emission efficiency of the construction industry in the province. Moreover, measures related to energy conservation and emission reduction in the construction industry should continue to boost sustainable development.

\section{TREATMENT MEASURES}

\section{Improve the Energy Utilization Efficiency and Optimize the Energy Consumption Structure}

China's construction industry is typically characterized by the rapid growth of economic aggregate and continuous increase of energy consumption and carbon emission. The energy intensity effect inhibits the growth process of carbon emission intensity in China's construction industry. Hence, the energy utilization efficiency must be improved to reduce the energy intensity effect, enhance the low-carbon consciousness of constructors, reasonably utilize energy sources, reduce the low-efficiency utilization and consumption of energy sources during the construction process, and promote their effective and cyclic utilization. The coal-centred energy consumption in China determines the unreasonable energy consumption structure of the construction industry. The carbon emission coefficient of coal is higher and more carbon is generated during its utilization process compared with those of other energy sources. The energy structure plays an inhibitory role in the growth process of carbon emission intensity. Thus, the energy consumption structure of the construction industry must be further optimized, the consumption of structure of various energy sources should be reasonably planned, and coal utilization should be applied. Moreover, the innovation level of low-carbon technologies should be elevated to accelerate the development and utilization of sustainable and green energy sources.

\section{Optimize the Utilization of Construction Materials and Enhance the Scientific and Technological Strength of Construction Enterprises}

The high carbon emission of the construction industry is mainly ascribed to the large usage amount of construction materials. The utilization of green construction materials should be promoted to improve energy utilization efficiency and reduce carbon emissions effectively. The government can encourage construction enterprises to utilize new-type, energy-saving, and renewable construction materials as well as encourage and support construction material manufacturers to produce green construction materials, transform relevant applied technologies, and improve the technological innovation level and competitiveness of construction enterprises in Henan Province further. Furthermore, the recycling of construction solid wastes should be reinforced. Technologies that realize the resource utilization of construction wastes should be aggressively developed, with emphasis on the treatment and recycling of construction wastes. Production technologies and processes of renewable construction materials should be updated. Enterprises must be supported for technological innovation of green construction materials. The design of high-efficiency equipment should be improved to solve the recycling problem of construction solid wastes effectively and promote the green and energy conservation development of the construction industry in Henan Province further. The current energy structure of the construction industry in Henan Province focuses on coal and petroleum utilization, and coal resources play a decisive role in the industrialization development of the construction industry. Hence, the utilization and innovation of coal desulfurization, clean coal, and energy recycling technologies should be strengthened to improve the utilization efficiency and recycling rate of energy sources, such as coal, substantially. The production equipment and processes can be improved through low-carbon technological innovation and the development of new-type materials that can replace energy sources while reducing the utilization rate of fossil fuels.

\section{Strengthen the Pollutant Discharge Management of the Construction Industry and Improve the Resource Utilization Efficiency}

The low comprehensive carbon emission efficiency of the construction industry in Henan Province indicated that the resource utilization efficiency of the industry requires urgent improvement and the management level of construction remains unchanged. Therefore, the management level of the construction industry in Henan Province should be improved to enhance resource utilization efficiency. The government can first reinforce the guidance of the construction industry by optimizing the system. Construction enterprises should then improve their management level internally and conduct appropriate adjustments in their organizational structure depending on actual conditions. Although the comprehensive efficiency of the construction industry in Henan Province is generally low, the relatively efficient level can be reached 
by altering the management pattern, adjusting inputs and outputs, and introducing relevant technical equipment. The input scale of the construction industry in Henan Province is enlarged, but the scale efficiency demonstrates disproportionate growth. Hence, the scale is independently expanded while the sustainable efficiency improvement of the construction industry is unrealized. This finding indicated that the efficiency improvement of the construction industry in Henan Province can be achieved by expanding not only its industrial-scale but also transforming the extensive inputdriven economic growth mode, with emphasis on improving technologies in the construction industry and elevating technological content.

\section{Enhance the Propaganda of Building Emission Reduction Policies and Improve the Autonomous Emission Reduction Awareness of the General Public}

The promoting effect of per capita building area is demonstrated by the improvement of building carbon emission efficiency under the enlarged per capita area. However, the energy utilization mode of the general public will make a difference and acceptable energy utilization behaviour can reduce building carbon emissions. The increase of building carbon emissions during the urbanization progress due to the increasing proportion of urban population indicated that the energy utilization mode of the urban population must continue to improve. A low-carbon society should be continuously advocated, and low-carbon economic development should be encouraged. Low-carbon economic development can be combined with a low-carbon lifestyle to improve population quality, drive the recycling efficiency of resources, mitigate the environmental pollution status, improve environmental conditions, and reduce building carbon emissions. The operation phase of building carbon emission during the development process is integrated with the energy utilization of the general public, and the energy utilization mode and habit directly influence the amount of building carbon emissions. Therefore, building emission reduction and environmental awareness of people should be enhanced continuously, the green energy consumption habit must be upheld, and repeated consumption should be avoided. Relevant sectors must reinforce the propaganda of low-carbon lifestyle, popularize low-carbon knowledge, formulate incentive measures for adopting a low-carbon lifestyle, and gradually enhance the awareness of public autonomous emission reduction in the improvement of public autonomous emission reduction awareness.

\section{CONCLUSION}

The construction industry is one of three major fields that generate greenhouse gas emissions worldwide. The proportion of energy consumption in industrial production will decline while that of construction energy consumption will continue to grow with the continuous progress of industrial technologies and the elevation of residential living standard. Improving the carbon emission efficiency of the construction industry is the precondition for reducing the total carbon emissions of the construction industry and promoting the reasonable establishment of the building carbon trading mechanism. The $\mathrm{CO}_{2}$ emission of the construction industry was taken as the unexpected output and then incorporated into the super efficiency SBM-DEA model to measure the carbon emission efficiency of the construction industry in Henan Province, China in the study period of 2008-2019. The results showed that the mean carbon emission efficiency of the construction industry during 2008-2019 is 1.007 and reached the minimum $(0.807)$ in 2012. The carbon emission efficiency of the construction industry in Henan Province realized an overall rising trend during the investigation period, but the amplitude was small. Accordingly, the following treatment measures were proposed: improve the energy utilization efficiency, scientific and technological strength of construction enterprises, resource utilization efficiency, propaganda of building emission reduction policies, and public autonomous emission reduction awareness; optimize the energy consumption structure and utilization of construction materials; and reinforce the pollutant discharge management of the construction industry. An in-depth study can be carried out in the future from the following aspects: accounting scope of building carbon emission, carbon emission database of the construction industry, influencing factors of building carbon emission, and digging of the emission reduction potential of the construction industry.

\section{ACKNOWLEDGEMENT}

This work was supported by the practice project of new engineering research in Henan Province (2020JGLX091), the key scientific research project plan of Henan Province Colleges and Universities(21B130001).

\section{REFERENCES}

Acquaye, A., Dadhich, P., Genovese, A. and Kumar, N. 2015. Developing sustainable supply chains in the UK construction industry: a case study. International Journal of Production Economics, 164.

Cole, R. J. 1999. Energy and greenhouse gas emissions associated with the construction of alternative structural systems. Building and Environment, 34(3): 335-348.

Cai, W., Feng, W., Huo, T., Ren, H., Wang, X., Zhang, X. and Zhou, N. 2018. China's energy consumption in the building sector: a statistical yearbook-energy balance sheet based splitting method. Journal of Cleaner Production, 185(JUN.1): 665-679.

Colombier, M. and Li, J. 2009. Managing carbon emissions in china through building energy efficiency. Journal of Environmental Management, 
90(8): 2436-2447.

Chau, K. W. and Wang, Y. S. 2001. An assessment of the technical efficiency of construction firms in Hong Kong. International Journal of Construction Management, 1(1): 21-29.

Du, Q., Lu, X., Wu, M., Xu, Y. and Yu, M. 2018. Club convergence and spatial distribution dynamics of carbon intensity in china's construction industry. Natural Hazards, 94: 519-536.

Fan, L., Hui, Y., Lei, Z., Shen, Q. and Wang, Y. 2010. Greenhouse gas emissions in building construction: a case study of one Peking in Hong Kong. Building and Environment, 45(4): 949-955.

Fang, Y., Li, H., Ma, Z. and Ng, S. T. 2018. Quota-based carbon tracing model for construction processes in China. Journal of Cleaner Production, 200: 657-666.

Huang, L., Johansen, F., Krigsvoll, G., Liu, Y. and Zhang, X. 2018. Carbon emission of global construction sector. Renewable and Sustainable Energy Reviews, 81(2):1906-1916.

Li, C. Q., Luo, W., Sandanayake, M., Setunge, S. and Zhang, G. 2017. Estimation and comparison of environmental emissions and impacts at foundation and structure construction stages of a building-a case study. Journal of Cleaner Production, 151: 319-329.
Lu, W., Tam, V., Chen, H. and Du, L. 2020. A holistic review of research on carbon emissions of green building construction industry. Engineering, Construction and Architectural Management, 27(5), 1065-1092.

Monahan, J. and Powell, J. C. 2011. A comparison of the energy and carbon implications of new systems of energy provision in new build housing in the UK. Energy Policy, 39(1): 290-298.

Ramanathan, R. 2006. A multi-factor efficiency perspective to the relationships among world GDP, energy consumption and carbon dioxide emissions. Technological Forecasting. Social Change, 73(5): 483-494.

Tone, K. 2001. A slacks-based measure of efficiency in data envelopment analysis. European Journal of Operational Research, 130(3): 498-509.

Wang, F. and Zhang, X. 2017. Life-cycle carbon emission assessment and permit allocation methods: a multi-region case study of china's construction sector. Ecological Indicators, 72: 910-920.

Zhou, Y., Liu, W., Lv, X., Chen, X. and Shen, M. 2019. Investigating interior driving factors and cross-industrial linkages of carbon emission efficiency in china's construction industry: based on supersbm dea and gvar model. Journal of Cleaner Production, 241: 118322. 